Revista Brasil. Bot., V.32, n.4, p.725-736, out.-dez. 2009

\title{
Análise da similaridade florística entre florestas do Alto Rio Xingu, da Bacia Amazônica e do Planalto Central ${ }^{1}$
}

\author{
SUSTANIS HORN KUNZ ${ }^{2,4}$, NATÁLIA MACEDO IVANAUSKAS ${ }^{3}$, \\ SEBASTIÃO VENÂNCIO MARTINS², ELIAS SILVA² e DANIEL STEFANELLO²
}

(recebido: 3 de abril de 2008; aceito: 26 de agosto de 2009)

\begin{abstract}
Analysis of floristic similarity between forests of the Upper Xingu River and forests of the Amazon Basin and of the Planalto Central). Recent studies have showed that the phytogeographic identity of the Upper Xingu River is as Seasonal Evergreen Forest. The region has peculiar physical and floristic characteristics, located at the contact area between the rain forest and the Brazilian Savannah (Cerrado). This study shows the floristic similarity between deciduous and semideciduous seasonal forests, cerrado of Middle Brazil and Amazonian tropical rain forests, aiming to interpret the relationship of the Seasonal Evergreen Forest of the Upper Xingu with one of these formations. Thirty-two lists of arbustive-arboreal species were taken from floristic and phytosociologic studies. The floristic similarity was estimated by Jaccard's index and the construction of dendrogram based on group mean values. The analysis of similarity allowed the identification of the clear floristic distinction between the Cerrado and the Amazon Forest biomes, as well as the areas of ecological tension between these biomes. The areas of seasonal evergreen forest were more similar to the monodominant semideciduous seasonal forest, which may be a consequence of their location in the ecotone between the Cerrado and the Amazon Forest. The low similarity between the Seasonal Evergreen Forest and the other forest types confirme the unique flora possessed by this phytophysiognomy, that demonstrates its recognition in a region considered as the transition area.
\end{abstract}

Key words - Amazon Forest, Brazilian savanna (Cerrado), Seasonal Evergreen Forest

RESUMO - (Análise da similaridade florística entre florestas do Alto Rio Xingu, da Bacia Amazônica e do Planalto Central). Por meio de estudos recentes, a identidade fitogeográfica do Alto Rio Xingu foi reconhecida como Floresta Estacional Perenifólia por apresentar características físicas e florísticas próprias, embora situada na área de contato entre a floresta ombrófila e o cerrado. Neste sentido, este estudo apresenta a similaridade florística entre florestas estacionais deciduais e semideciduais, Cerrado do Brasil Central e florestas ombrófilas amazônicas, buscando interpretar as relações entre a Floresta Estacional Perenifólia do Alto Xingu com uma ou outra formação. Foram selecionadas 32 listagens de espécies arbustivo-arbóreas de estudos florísticos/ fitossociológicos. A similaridade florística foi calculada por meio do índice de Jaccard e da construção de dendrograma baseado na média de grupo. A análise de similaridade permitiu identificar a clara distinção florística entre os biomas Cerrado e Floresta Amazônica, bem como as áreas de tensão ecológica entre estes biomas. As áreas de floresta estacional perenifólia foram mais similares com a floresta estacional semidecidual monodominante, o que pode ser explicado por estarem inseridas em uma região ecotonal entre o Cerrado e a Floresta Amazônica. A baixa similaridade da Floresta Estacional Perenifólia com os demais tipos florestais confirma a flora própria desta fitofisionomia, o que evidencia o seu reconhecimento em uma região considerada como área de transição.

Palavras-chave - Cerrado, Floresta Amazônica, Floresta Estacional Perenifólia

\section{Introdução}

A região amazônica apresenta uma série contínua de formações vegetais que são bem distintas floristicamente devido aos variados fatores ambientais que promovem diversas associações entre os componentes bióticos de

1. Parte da dissertação de mestrado da primeira autora, Universidade Federal de Viçosa, Programa de Pós-Graduação em Ciência Florestal.

2. Universidade Federal de Viçosa, Departamento de Engenharia Florestal, 36570-000 Viçosa, MG, Brasil.

3. Instituto Florestal do Estado de São Paulo, Divisão de Dasonomia, Seção de Ecologia Florestal. Rua do Horto, 931, Horto Florestal, 02377-000 São Paulo, SP, Brasil.

4. Autora para correspondência: sustanishk@yahoo.com.br cada ecossistema (Leitão-Filho 1987, Gama et al. 2003). Entre as formações vegetais que compõem esse bioma, existem as florestas de transição que ocorrem mais ao norte/nordeste do Estado de Mato Grosso, havendo certa dificuldade para compreender as denominações sugeridas a tais florestas.

Na região do Alto Xingu, a vegetação de transição foi denominada de "Floresta Associada ao Planalto dos Parecis”, sendo descrita como uma vegetação ecotonal, onde as espécies florestais ombrófilas e estacionais se misturam aleatoriamente, sem estarem associadas a um determinado tipo de clima, solo e/ou relevo (Seplan 1999). Ferreira et al. (1999) dividiu o bioma Amazônico em ecorregiões, mapeando essa mesma vegetação ecotonal como "ecorregião das florestas secas do Mato 
Grosso”, que também se sobrepõe àquela definida como área de tensão ecológica por Veloso et al. (1991). No entanto, estudos recentes baseados em relações soloclima-vegetação sugerem a denominação de Floresta Estacional Perenifólia para as florestas do Alto Xingu, na borda sul-amazônica (Ivanauskas et al. 2008).

Diante da dificuldade de um mapeamento detalhado na área de contato entre a Floresta Ombrófila, a Floresta Estacional e o Cerrado, estudos florísticocomparativos, como análises de agrupamento, são de extrema importância para reconhecer a identidade fitogeográfica do Alto Xingu. Tais estudos facilitam o entendimento da fitogeografia brasileira, pois permitem avaliar as semelhanças e as diferenças na composição de uma determinada comunidade vegetal com a de outras regiões, identificando possíveis correlações com variáveis ambientais (Meira-Neto \& Martins 2002). Além disso, estudos dessa natureza são úteis na avaliação da heterogeneidade ambiental, tendo também grande aplicação na definição de ecossistemas de referência em projetos de restauração florestal.

Nesse contexto, este estudo apresenta a similaridade florística entre florestas estacionais deciduais e semideciduais, Cerrado do Brasil Central e florestas ombrófilas amazônicas, buscando interpretar as relações entre a Floresta Estacional Perenifólia do Alto Xingu com uma ou outra formação.

\section{Material e métodos}

Elaborou-se um banco de dados compilando-se 32 listagens de espécies arbustivo-arbóreas amostradas em levantamentos florísticos e fitossociológicos realizados nos Estados de Mato Grosso, Rondônia, Amazonas, Pará, Maranhão, Distrito Federal, Tocantins e Goiás (figura 1). O sistema de classificação de vegetação usado está de acordo com Veloso et al. (1991) e Ribeiro \& Walter (1998). O banco de dados consistiu de uma matriz binária de presença e ausência de espécies, tendo sido consideradas apenas as fanerógamas com binômio completo, ou seja, foram excluídas identificações em nível de famílias e gêneros. A exclusão de indivíduos classificados apenas em nível de gênero e família é devido a dificuldade em se comparar estes taxas com aqueles identificados em nível de espécies (Salis et al. 1995), tornando os resultados da análise duvidosos ou tendenciosos.

Calculou-se a similaridade florística por meio do índice de Jaccard, seguindo a metolodogia de diversos autores (Silva \& Shepherd 1986, Torres et al. 1997, Durigan et al. 2003, Martins et al. 2004, Rossato et al. 2008). O índice de Jaccard considera o número de espécies comuns entre duas áreas (a) e o número de espécies exclusivas de cada área (b, c) (MuellerDombois \& Ellenberg 1974):

$$
J=100 \mathrm{a} /(\mathrm{a}+\mathrm{b}+\mathrm{c})
$$

Com base neste índice, elaborou-se um dendrograma baseado na média de grupo (UPGMA), no qual o agrupamento é feito a partir da média aritmética dos elementos, gerando um dendrograma, em que os valores das ordenadas expressam as relações de similaridade entre os objetos indicados nas abscissas (Sneath \& Sokal 1973). Para a ordenação dos dados foi utilizado o método Análise de Coordenadas Principais (PCO). A obtenção dos dados de similaridade foi realizada por meio dos programas do pacote FITOPAC I (Shepherd 1995).

\section{Resultados e discussão}

O número total de espécies amostradas, considerando todos os levantamentos comparados, foi de 1.310, distribuídas em 32 localidades (tabela 1), sendo que 768 espécies (58,6\%) foram registradas em apenas uma das áreas analisadas.

Poucas espécies tiveram ocorrência ampla, sugerindo que a maioria possui limitações ou preferências para ocupar ambientes restritos. As espécies de maior freqüência foram Tapirira guianensis Aubl., que ocorreu em 19 das 32 áreas amostradas, Maprounea guianensis Aubl. (16 áreas), Cheiloclinium cognatum (Miers) A. C. Sm., Hymenaea courbaril L. e Jacaranda copaia (Aubl.) D. Don (15 áreas).

Tapirira guianensis é uma espécie de distribuição ampla, pois ocorre em várias formações florestais assim como no Cerrado. Além desta, Maprounea guianensis e Cheiloclinium cognatum são consideradas espécies generalistas, sendo comuns em florestas e Cerrado, embora a luz solar seja considerada um fator chave ao desenvolvimento destas espécies (Oliveira-Filho \& Ratter 1995, 2000).

A análise de agrupamento revelou a formação de grupos com baixos níveis de similaridade (figura 2). Embora seja evidente a heterogeneidade florística entre os tipos florestais, três grandes grupos podem ser identificados na análise de agrupamento. O grupo I é formado por áreas de cerradão de Mato Grosso e Tocantins, de floresta estacional semidecidual de Mato Grosso e de florestas de galeria do Distrito Federal e Goiás. O grupo II é formado por trechos de floresta estacional perenifólia da Bacia do rio das Pacas e do Pacuneiro, de floresta estacional monodominante na região nordeste de Mato Grosso e uma área de floresta ombrófila do Maranhão. O grupo III é constituído por áreas de floresta ombrófila amazônica situadas no Pará, Amazonas, Rondônia e Maranhão. 


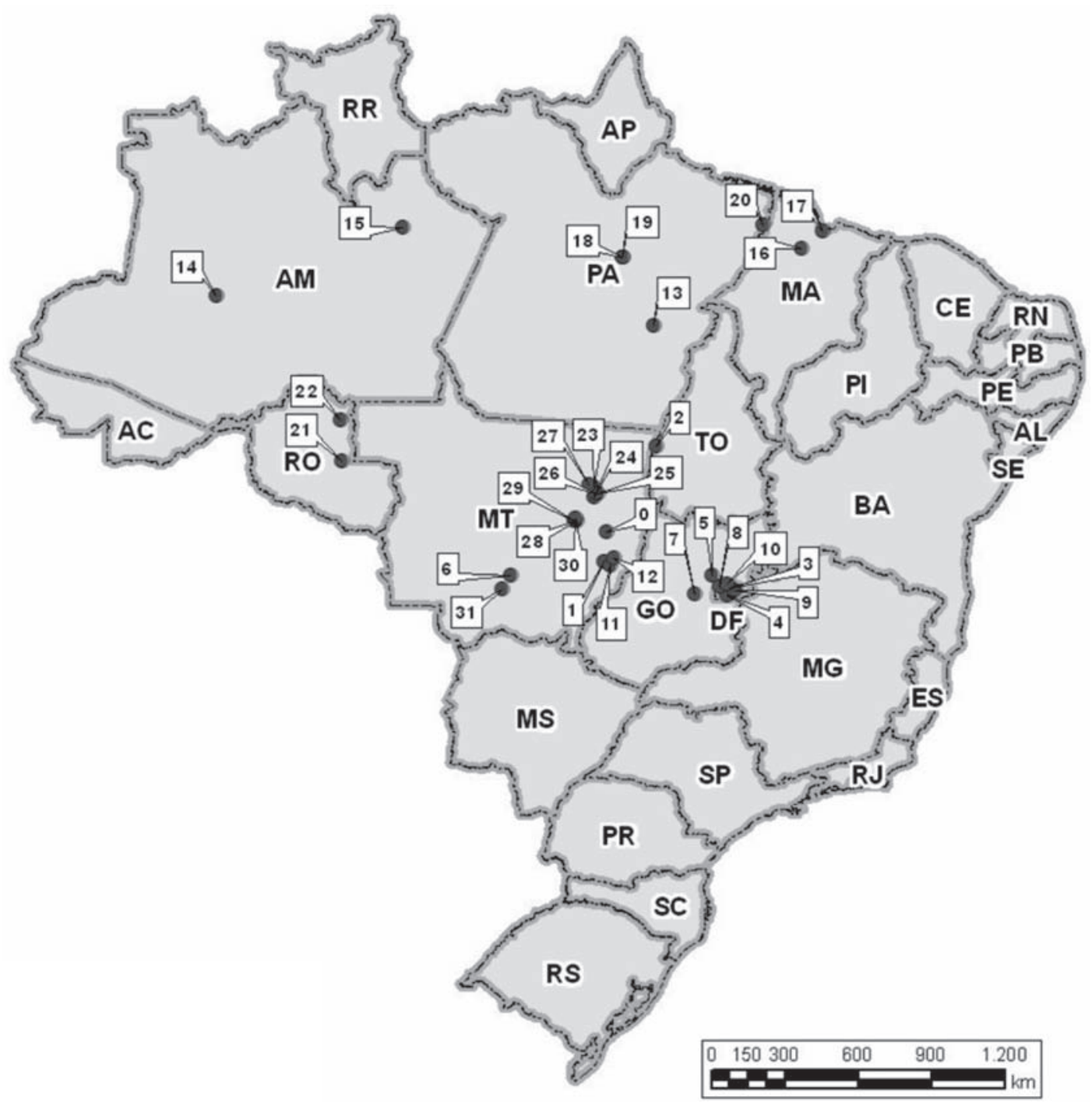

Figura 1. Localização das áreas de florestas do Alto Xingu, outras formações florestais amazônicas e do Planalto Central utilizadas na análise de similaridade florística (as siglas em parênteses correspondem aos códigos da tabela 1). 0. CanaranaMT (C1); 1. Nova Xavantina-MT (C2); 2. Pq. Nacional do Araguaia-TO (C3); 3. Planaltina-DF (C4); 4. Brasília-DF (C5); 5. Brasília-DF (C6); 6. Chapada dos Guimarães-MT (FG1); 7. APA do Gama Cabeça do Veado-DF (FG2); 8. P. N. de BrasíliaDF (FG3); 9. Rio Jardim-GO (GF4); 10. APA do Cafuringa-DF (FG5); 11. Nova Xavantina-MT (FM1); 12. Água Boa-MT (FM2); 13. Marabá-PA (FO0); 14. Caruari-AM (FO1); 15. Manaus-AM (FO2); 16. Bacia do rio Turiaçu-AM (FO3); 17. São Luís-MA (FO4); 18. Rio Xingu-PA (FO5); 19. Rio Xingu-PA (FO6); 20. Bacia do rio Gurupi-PA (FO7); 21. BR - 364-RO (FO8); 22. Jaru-RO (FO9); 23. Querência-MT (FP1); 24. Querência-MT (FP2); 25. Querência-MT (FP3); 26. Querência-MT (FP4); 27. Querência-MT (FP5); 28. Gaúcha do Norte-MT (FP6); 29. Gaúcha do Norte-MT (FP7); 30. Gaúcha do Norte-MT (FP8); 31. Cuiabá-MT (FS). (• = Pontos de amostragem).

Figure 1. Forests areas of the Upper Xingu, other Amazonian forest formations and the Central Plateau, included in the floristic similarity analysis (the symbols in parentheses match the codes of table 1). 0. Canarana-MT (C1); 1. Nova Xavantina-MT (C2); 2. Pq. Nacional do Araguaia-TO (C3); 3. Planaltina-DF (C4); 4. Brasília-DF (C5); 5. Brasília-DF (C6); 6. Chapada dos GuimarãesMT (FG1); 7. APA do Gama Cabeça do Veado-DF (FG2); 8. P. N. de Brasília-DF (FG3); 9. Rio Jardim-GO (GF4); 10. APA do Cafuringa-DF (FG5); 11. Nova Xavantina-MT (FM1); 12. Água Boa-MT (FM2); 13. Marabá-PA (FO0); 14. Caruari-AM (FO1); 15. Manaus-AM (FO2); 16. Bacia do rio Turiaçu-AM (FO3); 17. São Luís-MA(FO4); 18. Rio Xingu-PA (FO5); 19. Rio Xingu-PA (FO6); 20. Bacia do rio Gurupi-PA (FO7); 21. BR - 364-RO (FO8); 22. Jaru-RO (FO9); 23. Querência-MT (FP1); 24. Querência-MT (FP2); 25. Querência-MT (FP3); 26. Querência-MT (FP4); 27. Querência-MT (FP5); 28. Gaúcha do NorteMT (FP6); 29. Gaúcha do Norte-MT (FP7); 30. Gaúcha do Norte-MT (FP8); 31. Cuiabá-MT (FS). (• = Sampling points). 


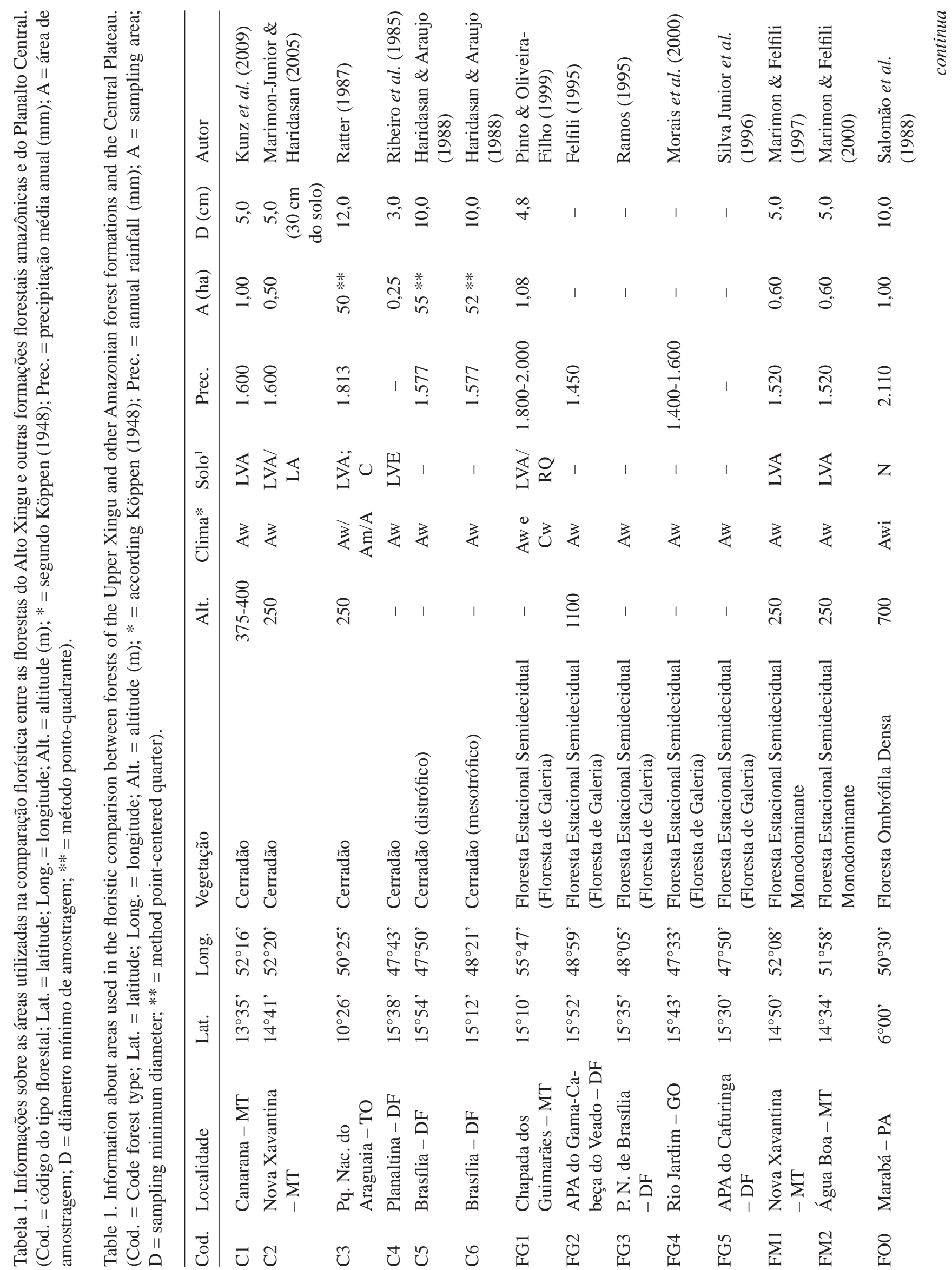




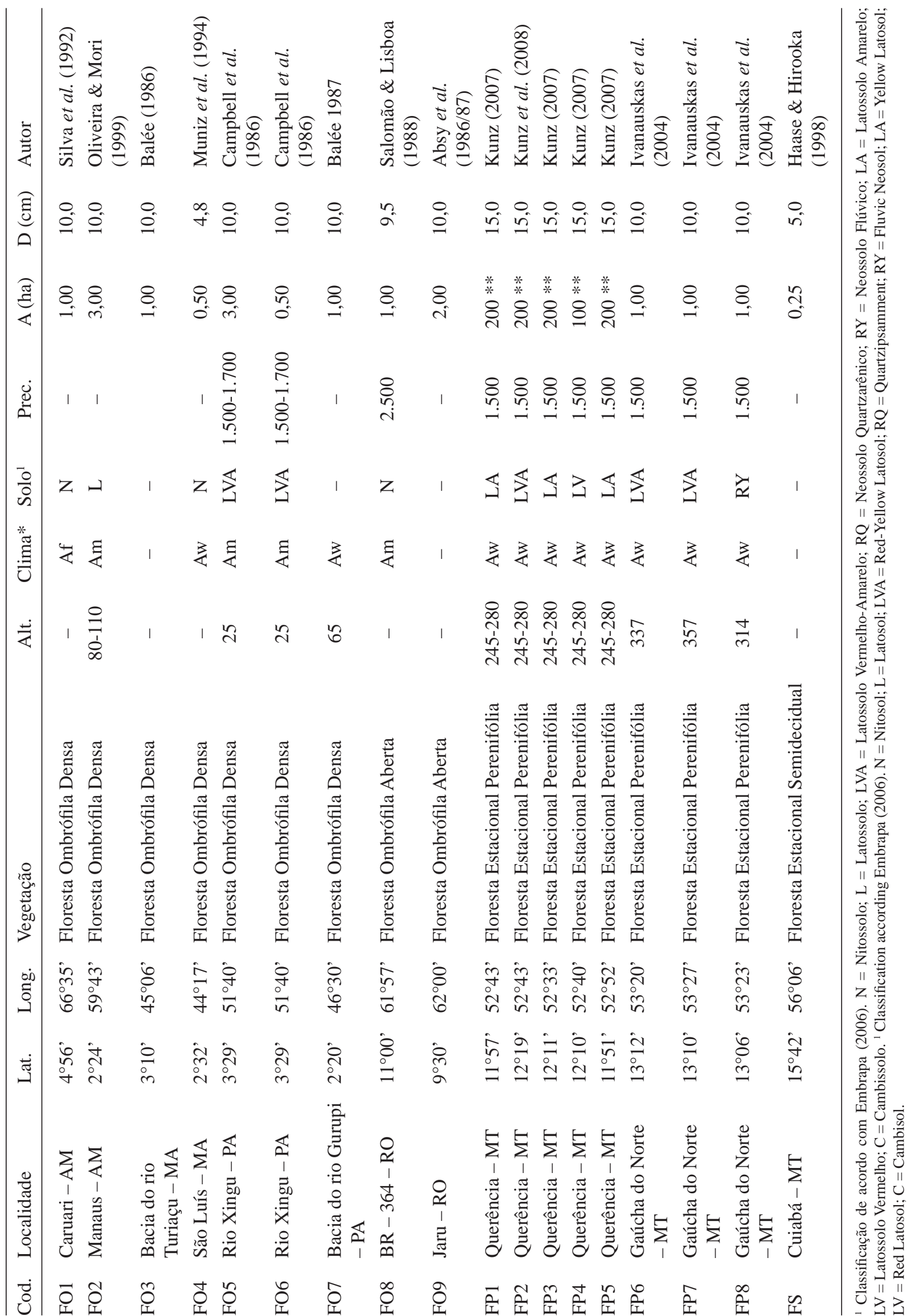


Duas ou mais áreas são consideradas similares em termos de composição florística quando apresentam pelo menos 25\% de espécies comuns (MuellerDombois \& Ellenberg 1974). Considerando este valor, ocorrem algumas subdivisões nos três grupos citados anteriormente, sendo que as áreas de maior similaridade florística são as de floresta estacional perenifólia da Bacia do rio das Pacas (FP1, FP2, FP3, FP4, FP5 - figura 2).

É interessante ressaltar que a análise de similaridade mostra clara distinção florística entre os domínios de Cerrado (C1 a C6, FG1 a FG5, FS) e de Floresta Amazônica (FO0 a FO9), bem como as áreas de tensão ecológica (FP1 a FP8, FM1, FM2) que formaram o segundo agrupamento (figura 2). Ivanauskas et al. (2008) relataram que a composição florística e estrutural da
Floresta Estacional Perenifólia e os fatores físicos do ambiente são diferentes daqueles que ocorrem nas áreas adjacentes de Cerrado e Floresta Amazônica, o que não a caracteriza como vegetação de transição.

Apesar de condicionadas ao mesmo tipo climático (Aw), com temperatura média em torno de $25^{\circ} \mathrm{C}$ e precipitação média anual de 1.500-1.800 mm, a baixa similaridade florística entre as áreas de floresta estacional perenifólia e o primeiro agrupamento pode ser atribuída à distância geográfica, fertilidade do solo e profundidade do lençol freático. Distinções florísticas podem existir mesmo entre florestas de galeria e a vegetação circunvizinha devido a influência dos fatores antrópicos, edáficos e hidrogeomorfológicos, como altura do lençol freático e topografia (Correia et al. 2001). Já as florestas

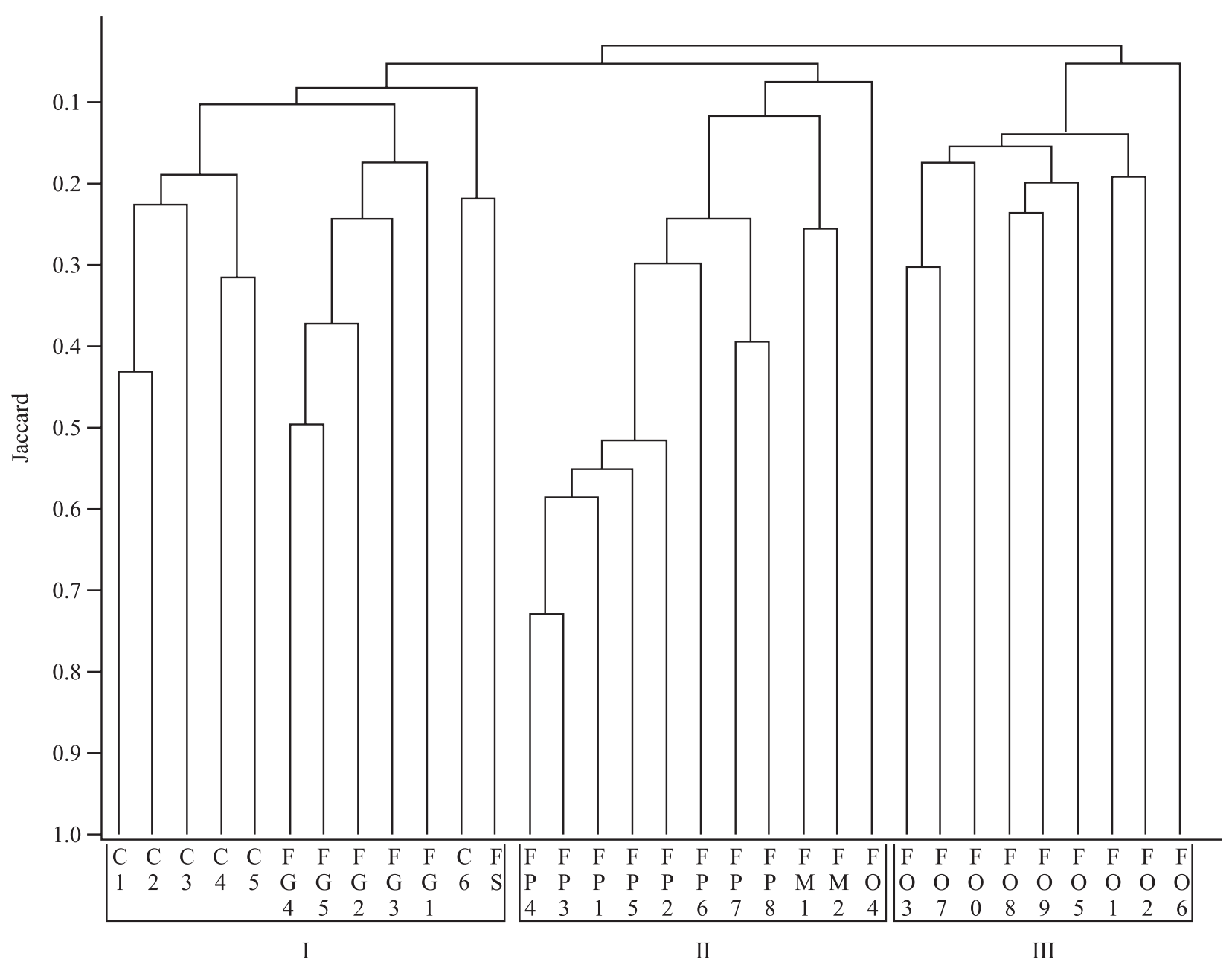

Figura 2. Dendrograma de análise de agrupamento (UPGMA), utilizando o índice de similaridade de Jaccard, para as áreas de floresta do Alto Xingu e outras formações florestais amazônicas e do Planalto Central (as siglas correspondem aos códigos da tabela 1).

Figure 2. Cluster analysis dendrogram (UPGMA), based upon Jaccard's Similarity Index, to the areas of forest of the Upper Xingu and other Amazonian forest formations and the Central Plateau (the symbols match the codes of table 1). 
ciliares e de galerias do noroeste do Cerrado, que se encontram na faixa de transição entre o Cerrado e a Floresta Amazônica, apresentam alta similaridade com a flora Amazônica em função da direção de quase todos os rios da região noroeste ser para o rio Amazonas, principalmente aqueles que fluem nas depressões periféricas (Oliveira-Filho \& Ratter 2000).

Embora várias espécies amazônicas penetrem nos cerrados por meio das matas ciliares (Rizzini 1979, Oliveira-Filho \& Ratter 2000), no presente trabalho não foi constatada alta semelhança entre as florestas do domínio amazônico e aquelas florestas de galeria do Distrito Federal (figura 2).

A baixa similaridade pode ser explicada pela posição geográfica das florestas de galeria, as quais estão localizadas no domínio de Cerrado do Brasil Central. Fato semelhante foi constatado por Oliveira-Filho \& Ratter (1995), os quais observaram que as florestas de galeria do Distrito Federal, Goiás e Minas Gerais, pertencentes à Bacia Hidrográfica do Paraná e São Francisco, são mais semelhantes floristicamente às florestas do Paraná, ao passo que as florestas de galeria de Mato Grosso e Tocantins apresentam maior ligação florística com a Floresta Amazônica. Estes autores também afirmam que a ligação florística entre florestas de galerias, florestas ombrófilas e outras semidecíduas é devido à semelhança no teor de umidade dos solos, embora nas margens dos cursos d'água a umidade possa ser bem mais baixa que em florestas ombrófilas.

Desta forma, há certa limitação para a distribuição de espécies ombrófilas ou semidecíduas, ao passo que a flora dos cerradões, principalmente do tipo distrófico, apresentam laços florísticos mais fortes com as florestas de galeria (Oliveira-Filho \& Ratter 2000). Copaifera langsdorfii Desf. é considerada uma espécie característica de solos menos úmidos, pois na análise de similaridade esteve presente apenas em áreas de cerradão distrófico e mesotrófico, florestas de galeria e floresta estacional perenifólia, confirmando as observações feitas por Oliveira-Filho \& Ratter (1995), os quais afirmam que tal espécie ocorre sob clima Aw e Cw além de ser generalista por habitat, com ocorrência em vários tipos de solos tanto no cerrado quanto em áreas de floresta.

Adicionalmente, estes autores apontam Hirtella glandulosa Spreng., Emmotum nitens (Benth.) Miers, Physocalymma scaberrimum Pohl e Vochysia haenkeana Mart. como espécies comuns em florestas de galeria, florestas de transição e cerradões. Apenas Physocalymma scaberrimum foi registrada em uma das áreas de floresta estacional perenifólia em Gaúcha do Norte, evidenciando a fraca ligação desta fitofisionomia com outros tipos florestais do domínio Cerrado. Analisando a similaridade florística entre florestas secas sazonais da América do Sul, Oliveira-Filho et al. (2006), observaram que o gradiente florístico existente entre florestas perenifólias, semidecíduas e decíduas está diretamente relacionado com o decréscimo da disponibilidade de água tanto através do aumento da sazonalidade das chuvas como do decréscimo do teor de umidade do solo. Além disso, os gradientes de temperatura e fertilidade do solo, bem como a freqüência de queimadas são fatores que atuam na distribuição das espécies.

Por outro lado, Méio et al. (2003) relatam que as espécies amazônicas penetram menos no Cerrado que as espécies da Floresta Atlântica. Os autores chegaram a esta conclusão por meio de uma análise da influência da flora Amazônica e Atlântica no cerrado sensu stricto, onde observaram diminuição na proporção de espécies da Hiléia à medida que se avança para o centro do bioma Cerrado.

A similaridade florística geralmente é alta quando se considera o mesmo tipo de unidade vegetacional, a proximidade espacial e a ocorrência das áreas analisadas na mesma bacia hidrográfica (Rodrigues \& Nave 2000). A composição florística da comunidade também pode apresentar variações devido aos fatores espaciais e ambientais (Cottenie 2005) tais como clima, precipitação, temperatura e condições edáficas, que influenciam a distribuição das espécies e atuam diretamente na similaridade florística entre as áreas (Meira-Neto et al. 1989, Ivanauskas et al. 2000, Marimon et al. 1998, Oliveira \& Nelson 2001, Oliveira-Filho et al. 2001, Brotel et al. 2002).

As áreas de floresta estacional perenifólia de Gaúcha do Norte (FP6, FP7 e FP8) e de Querência (FP1, FP2, FP3, FP4 e FP5) apresentaram baixa similaridade florística, ao contrário do esperado, uma vez que existe um continuum florestal e homogeneidade do ambiente físico, fato constatado em estudos desenvolvidos por Ivanauskas et al. (2003, 2008). Estas áreas, assim como aquelas do Pará (FO5 e FO6 - Campbell et al. 1986), pertencem a Bacia Hidrográfica do Xingu, sugerindo que bacias hidrográficas muito extensas, como é o caso desta, podem apresentar um mosaico espacial de fatores físicos que interagem de forma diferente, propiciando diferenças florísticas mesmo entre áreas próximas.

Já as florestas da Bacia do Pacuneiro apresentaram alta similaridade entre elas (FP6, FP7 e FP8), assim como entre aquelas da bacia do Pacas (FP1, FP2, FP3, FP4 e FP5, figura 2), evidenciando a influência de bacias menores sobre a distribuição das espécies. Apenas Amaioua guianensis Aubl., Aspidosperma discolor 
A. DC., Hirtella racemosa Lam., Ocotea leucoxylon (Sw.) Laness., Sloanea eichleri K. Schum. e Xylopia amazonica R. E. Fr., foram amostradas em todas as áreas de Gaúcha do Norte e Querência-MT, sendo consideradas espécies comuns em floresta estacional perenifólia. Além destas, Chaetocarpus echinocarpus (Baill.) Ducke, Guatteria schomburgkiana Mart., Ocotea guianensis Aubl., Ouratea discophora Ducke, Protium pilosissimum Engl. e Trattinnickia glaziovii Swart foram registradas em pelo menos sete das oito áreas de floresta estacional perenifólia analisadas no presente estudo.

Tuomisto \& Ruokolainen (1997) e Rossi \& QueirozNeto (2001) relatam que a vegetação está diretamente relacionada à topografia, cujo aspecto reflete na profundidade do solo e do lençol freático, assim como outras características, e por isto a composição florística torna-se diferente mesmo em curtas distâncias. Embora o relevo suave seja o tipo predominante onde ocorre a Floresta Estacional Perenifólia, as áreas de Gaúcha do Norte e Querência-MT estão em altitudes diferentes (314-357 m e 245-280 m, respectivamente), explicando em parte, a diferenciação florística entre as mesmas, bem como os diferentes níveis de perturbação antrópica entre elas.

A ligação florística entre a Floresta Estacional Perenifólia e os trechos de floresta estacional semidecidual monodominante (FM1 e FM2) é atribuída ao fato de estarem inseridas em uma região de tensão ecológica entre o Cerrado e a Floresta Amazônica (Marimon et al. 2001), mas o elo de ligação entre estes dois tipos florestais é fraco (figura 2). Estas florestas são consideradas monodominantes devido a abundância de Brosimum rubescens Taub., uma espécie endêmica da Bacia Amazônica. Por apresentar ligação florística com a floresta ombrófila, esta fitofisionomia é considerada floresta de transição (Ivanauskas et al. 2008).

Já a distinção florística entre a Floresta Ombrófila e a Floresta Estacional Perenifólia é explicada pelas flutuações climáticas que ocorreram durante o Quaternário, as quais são apontadas como uma das causas da expansão e retração das formações abertas e florestas úmidas no Brasil (Brown \& Ab’Sáber 1979, Ledru 1993, Salgado-Labouriau et al. 1997, OliveiraFilho \& Ratter 2000, Méio et al. 2003), influenciando na distribuição das espécies vegetais.

As áreas de floresta ombrófila situam-se em altitudes mais baixas (25 a $110 \mathrm{~m}$ ) que as demais áreas florestais (tabela 1), havendo efeitos sobre a distribuição florística, mesmo entre o contato Cerrado/Floresta Amazônica. Durante o Quaternário, a depressão geomorfológica entre o Cerrado e a Floresta Amazônica era muito instável e essa conexão pode ter sofrido mudanças ecológicas muito drásticas, impedindo que a flora amazônica avançasse sobre as áreas mais abertas (Silva 1996).

$\mathrm{Na}$ zona de contato entre esses dois biomas também ocorre aumento da latitude, que coincide com a diminuição da temperatura mínima no inverno na direção sul e aumento do período seco em direção ao Brasil Central (Nimer 1979, Oliveira-Filho \& Ratter 2000), enquanto que em áreas de altitude mais elevada ocorre diminuição da pressão atmosférica e aumento da velocidade do vento e da radiação solar, interferindo fundamentalmente na variação anual do período de luz solar diária (Jones 1994). Diante disso, observase que as variações florísticas encontradas entre os três agrupamentos podem ter sido influenciadas pela diferença latitudinal, pois no grupo III as áreas estão entre as latitudes $2^{\circ}$ e $11^{\circ}$; o grupo II possui áreas com latitudes $13^{\circ}$ e $14^{\circ}$, com exceção de FO4 (latitude $2^{\circ}$ ) e o grupo I variou de $10^{\circ}$ a $15^{\circ}$. Fato semelhante também foi constatado por Oliveira-Filho \& Ratter (1995), ao compararem a distribuição das florestas brasileiras por meio do diagrama de dispersão, onde o agrupamento das localidades foi fortemente influenciado pela latitude e precipitação sazonal.

A precipitação sazonal é mais importante para determinar a presença de florestas estacionais ou florestas úmidas em uma determinada área, pois a ausência de chuvas por um período de 30 dias já é suficiente para provocar efeitos sobre a vegetação e agir como um fator limitante à distribuição das espécies (IBGE 1993). Desta forma, além da precipitação média anual ser maior em trechos de floresta ombrófila (2.750 mm, Nimer 1979, Oliveira \& Amaral 2004) do que na área de contato entre Cerrado e Floresta Amazônica (1.500 mm, Ivanauskas et al. 2008), a ocorrência de um período seco nesta região, que varia de quatro a seis meses, é considerada uma das grandes barreiras à permanência de espécies ombrófilas em um clima estacional (Ivanauskas et al. 2008). As espécies vegetais típicas de florestas tropicais úmidas são muito exigentes em relação à disponibilidade de água, sendo necessário haver a ocorrência de chuvas regularmente distribuídas durante todo o ano (Eyre 1984).

Em trechos de florestas de terra firme do domínio amazônico sujeitas a longos períodos de seca, a absorção de água pode ocorrer a oito metros de profundidade, havendo raízes que alcançam até 18 metros, embora seja encontrada maior quantidade de raízes na camada mais superficial do solo (Nepstad et al. 1994). Esta característica pode ser atribuída à Floresta Estacional Perenifólia, principalmente quando se considera a 
ocorrência da mesma sobre latossolos, os quais facilitam a penetração das raízes para absorção de água em maiores profundidades, como observado em Gaúcha do Norte, MT onde o nível do lençol freático mantém-se abaixo de 2 metros durante todo o ano (Ivanauskas et al. 2008).

Características climáticas e geoquímicas são fatores que contribuem simultaneamente para a diferenciação florística (Tuomisto et al. 2003). Ainda que características geoquímicas não estejam explícitas, o clima e o tipo de solo em que a Floresta Ombrófila e Floresta Estacional Perenifólia ocorrem são diferentes. Nas áreas FO1, FO2, FO8, ocorre o clima tropical úmido (Af ou Am) de acordo com a classificação de Köppen, enquanto as áreas de floresta estacional perenifólia estão sujeitas ao clima tropical, que apresenta inverno seco (Aw). Contudo, em algumas áreas de floresta ombrófila (FO9 e FO0), o clima é caracterizado também como Aw, sugerindo que a similaridade florística deve ser analisada com base em um conjunto de fatores físicos do ambiente.

Além destes fatores, longas distâncias geográficas são consideradas aspectos importantes para a diferenciação florística, além das características de cada área, como o grau de perturbação do ambiente e a fitofisionomia, aliada à precipitação (Terborgh \& Andresen 1998, Oliveira \& Nelson 2001). Neste contexto, a comparação florística entre floresta estacional perenifólia, florestas estacionais semideciduais, cerrado e florestas ombrófilas amazônicas permitiu identificar que as características físicas do ambiente, aliado à evolução das paisagens proporcionaram distinções entre estes tipos florestais. Contudo, o conhecimento acerca das características ambientais da região de abrangência da floresta estacional perenifólia ainda é insuficiente para afirmar com clareza a atuação de um ou outro fator sobre a distribuição das espécies vegetais.

Ainda assim, a nítida separação florística das florestas do Cerrado, da região amazônica e aquelas situadas em uma região de tensão ecológica mostra que a heterogeneidade ambiental e a distância geográfica atuam sobre a distribuição das espécies ao longo dos trechos florestais. A separação da Floresta Estacional Perenifólia dos demais tipos florestais confirma a flora própria que esta fitofisionomia possui (Ivanauskas et al. 2008), embora mantenha algum laço florístico com as florestas estacionais semideciduais monodominantes.

Novos estudos florísticos e fitossociológicos são necessários para melhor esclarecimento da identidade da Floresta Estacional Perenifólia, permitindo maiores conclusões acerca dessa fitofisionomia, bem como da área de abrangência da mesma. O conhecimento do ambiente físico onde está inserida a Floresta Estacional
Perenifólia é igualmente importante, uma vez que sua relação com a vegetação pode melhor elucidar a distinção florística dos demais tipos vegetacionais em uma área que é considerada de transição.

\section{Referências bibliográficas}

ABSY, M.L., PRANCE, G.T. \& BARBOSA, E.M. 1986/1987. Inventário florístico de floresta natural na área da estrada Cuiabá-Porto Velho. Acta Amazonica 16/17:85-121.

BALÉE, W. 1986. Análise preliminar de inventário florestal e a etnobotânica Ka’apor (Maranhão). Boletim do Museu Paraense Emílio Goeldi, série Botânica 2:141-167.

BALÉE, W. 1987. Etnobotânica quantitativa dos índios Tembé (Rio Gurupi, Pará). Boletim do Museu Paraense Emílio Goeldi, série Botânica 3:29-50.

BROTEL, R.T., OLIVEIRA-FILHO, A.T., RODRIGUES, L.A. \& CURI, N. 2002. Influência do solo e topografia sobre as variações da composição florística e estrutura da comunidade arbóreo-arbustiva de uma floresta estacional semidecidual em Ingá, MG. Revista Brasileira de Botânica 25:195-213.

BROWN, K.S. \& AB'SÁBER, A.N. 1979. Ice-age forest refuges and evolution in the neotropics: correlation of paleoclimatological, geomorphological and pedological data with modern biological endemisms. Paleoclimas 5:1-30.

CAMPBELL, D.G., DALY, D.C., PRANCE, G.T. \& MACIEL, U.N. 1986. Quantitative ecological inventory of terra firme and várzea tropical forest on the Rio Xingu, Brazilian Amazonia. Brittonia 38:369-393.

CORREIA, J.R., HARIDASAN, M., REATTO, A., MARTINS, E.S. \& WALTER, B.M.T. 2001. Influência de fatores edáficos na distribuição de espécies arbóreas em Matas de Galeria na região do Cerrado: uma revisão. In Cerrado: caracterização e recuperação de Matas de Galeria. (J.F. Ribeiro, C.E.L. Fonseca \& J.C. Sousa-Silva, eds.). Embrapa Cerrados, Planaltina, p.61-76.

COTTENIE, K. 2005. Integrating environmental and spatial processes in ecological community dynamics. Ecology Letters 8:1175-1182.

DURIGAN, G., SIQUEIRA, M.F., FRANCO, G.A.D.C., BRIDGEWATER, S. \& RATTER, J.A. 2003. The vegetation of priority areas for cerrado conservation in São Paulo State, Brazil. Edinburgh Journal of Botany 60:217-241.

EMBRAPA. Centro Nacional de Pesquisa em Solos. 2006. Sistema brasileiro de classificação de solos. 2a ed. Embrapa Solos, Rio de Janeiro.

EYRE, S.R. 1984. Vegetation and soils: a world picture. $2^{2}$ ed. Edward Arnold, London.

FELFILI, J.M. 1995. Diversity, structure and dynamics of gallery forest in central Brazil. Vegetatio 117:1-15. 
FERREIRA, L.V., SÁ, R.L., BUSCHBACHER, R., BATMANIAN, G., SILVA, J.M.C., ARRUDA, M.B., MORETTI, E., SÁ, L.F.S.N., FALCOMER, J. \& BAMPI, M.L. 1999. Identificação de áreas prioritárias para a conservação da biodiversidade através da representatividade das unidades de conservação e tipos de vegetação nas ecorregiões da Amazônia Brasileira. In Avaliação e identificação de ações prioritárias para a conservação, utilização sustentável e repartição dos benefícios da biodiversidade da Amazônia brasileira: Programa Nacional da Diversidade Biológica. Seminário de Consulta, Macapá. http://www.isa.org.br. Acesso em 23 de março de 2009.

GAMA, J.R.V., BOTELHO, S.A., BENTES-GAMA, M.M. \& SCOLFORO, J.R.S. 2003. Estrutura e potencial futuro de utilização da regeneração natural de floresta de várzea alta no município de Afuá, estado do Pará. Ciência Florestal 13:71-82.

HAASE, R. \& HIROOKA, Y. 1998. Structure, composition and small litter dynamics of a semi-deciduous forest in Mato Grosso, Brazil. Flora: 141-147.

HARIDASAN, M. \& ARAÚJO, G.M. 1988. Aluminiumaccumulating species in two forest communities in the cerrado region of central Brazil. Forest Ecology and Management 24:15-26.

IBGE - Instituto Brasileiro de Geografia e Estatística. 1993. Recursos naturais e meio ambiente: uma visão do Brasil. Departamento de Recursos Naturais e Estudos Ambientais, Rio de Janeiro.

IVANAUSKAS, N.M., MONTEIRO, R. \& RODRIGUES, R.R. 2000. Similaridade florística entre áreas de Floresta Atlântica no Estado de São Paulo. Brazilian Journal of Ecology 1:71-81.

IVANAUSKAS, N.M., MONTEIRO, R. \& RODRIGUES, R.R. 2003. Relações florísticas entre florestas deciduais, semideciduais e perenifólias na região Centro-Oeste do Brasil. In Ecossistemas brasileiros: manejo e conservação (V. Claudino-Sales, org.). Expressão Gráfica e Editora, Fortaleza, p.313-322.

IVANAUSKAS, N.M., MONTEIRO, R. \& RODRIGUES, R.R. 2004. Estrutura de um trecho de floresta Amazônica na bacia do alto rio Xingu. Acta Amazonica 34:275-299.

IVANAUSKAS, N.M., MONTEIRO, R. \& RODRIGUES, R.R. 2008. Classificação fitogeográfica das florestas do Alto Rio Xingu. Acta Amazonica 38:387-402.

JONES, H.G. 1994. Plants and microclimate: a quantitative approach to environmental plant physiology. $2^{\mathrm{a}}$ ed. Cambridge University Press, Cambridge.

KÖPPEN, W.P. 1948. Climatologia. Fondo de Cultura Economica, Mexico.

KUNZ, S.H. 2007. Florística e estrutura da comunidade arbórea de trechos de Floresta Amazônica, Alto Rio Xingu, Mato Grosso, Brasil. Dissertação de mestrado, Universidade Federal de Viçosa, Viçosa.
KUNZ, S.H., IVANAUSKAS, N.M., MARTINS, S.V., SILVA, E. \& STEFANELLO, D. 2008. Aspectos florísticos e fitossociológicos de um trecho de Floresta Estacional Perenifólia na Fazenda Trairão, Bacia do rio das Pacas, Querência-MT. Acta Amazonica 38:245-254.

KUNZ, S.H., IVANAUSKAS, N.M. \& MARTINS, S.V. 2009. Estrutura de uma área de cerradão em Canarana - Estado do Mato Grosso, Brasil. Acta Scientiarum 31. No prelo.

LEDRU, M. 1993. Late quaternary environmental and climatic changes in central Brazil. Quaternary Research 39:90-98.

LEITÃO-FILHO, H.F. 1987. Considerações sobre a florística de florestas tropicais e sub-tropicais do Brasil. IPEF 35:41-46.

MARIMON, B.S. \& FELFILI, J.M. 1997. Structure of a monodominant forest of Brosimum rubescens Taub. in Nova Xavantina-MT, Brazil. In Proceedings of the Internacional Symposium on Assessment and Monitoring of Forests in Tropical Dry Regions with Special Reference to Gallery Forests. Brasília, UnB. Universidade de Brasília, Brasília, p.215-230.

MARIMON, B.S. \& FELFILI, J.M. 2000. Distribuição de diâmetros e alturas na floresta monodominante de Brosimum rubescens Taub. na Reserva Indígena Areões, Água Boa-MT, Brasil. Revista Árvore 24: 143-150.

MARIMON-JUNIOR, B.H. \& HARIDASAN, M. 2005. Comparação da vegetação arbórea e características edáficas de um cerradão e um cerrado sensu stricto em áreas adjacentes sobre solo distrófico no leste de Mato Grosso, Brasil. Acta Botanica Brasilica 19:913926.

MARIMON, B.S., VARELLA, R.F. \& MARIMON-JUNIOR, B. 1998. Fitossociologia de uma área de cerrado de encosta em Nova Xavantina, Mato Grosso. Boletim do Herbário Ezechias Paulo Heringer 3:82-101.

MARIMON, B.S., FELFILI, J.M. \& HARIDASAN, M. 2001. Studies in monodominant forests in eastern Mato Grosso, Brazil: II. A florest in the Areões Xavante Indian Reserve. Edinburgh Journal of Botany 58:483-497.

MARTINS, S.V., JÚNIOR, R.C., RODRIGUES, R.R. \& GANDOLFI, S. 2004. Colonization of gaps produced by death of bamboo clumps in a semideciduous mesophytic forest in south-eastern Brazil. Plant Ecology 172:121131.

MÉIO, B.B., FREITAS, C.V., JATOBÁ, L., SILVA, M.E.F., RIBEIRO, J.F. \& HENRIQUES, R.P.B. 2003. Influência da flora das florestas Amazônica e Atlântica na vegetação do cerrado sensu stricto. Revista Brasileira de Botânica 26:437-444.

MEIRA-NETO, J.A.A. \& MARTINS, F.R. 2002. Composição florística de uma floresta estacional semidecidual montana no município de Viçosa-MG. Revista Árvore 26:437-446. 
MEIRA-NETO, J.A.A., BERNACCI, L.C., GROMBONE, M. T., TAMASHIRO, J.Y. \& LEITÃO-FILHO, H.F. 1989. Composição florística da floresta semidecídua de altitude do Parque Municipal da Grota Funda (Atibaia, Estado de São Paulo). Acta Botanica Brasilica 3:51-74.

MORAIS, R.O., ENCINAS, J.I. \& RIBEIRO, J.F. 2000. Fitossociologia da Mata de Galeria da cabeceira do Rio Jardim/DF. Boletim do Herbário Ezechias Paulo Heringer 5:44-61.

MUELLER-DOMBOIS, D. \& ELLENBERG, H. 1974. Aims and methods vegetation ecology. J. Wiley, New York.

MUNIZ, F.H., CESAR, O. \& MONTEIRO, R. 1994. Fitossociologia da vegetação arbórea da Reserva Florestal do Sacavém, São Luís, Maranhão (Brasil). Acta Amazonica 24:219-236.

NEPSTAD, D.C., CARVALHO, C.R., DAVIDSON, E.A., JIPP, P.H., LEFEBVRE, P.A., NEGREIROS, G.H., SILVA, E.D., STONE, T.A., TRUMBORE, S.E. \& VIEIRA, S. 1994. The role of deep roots in the hydrological and carbon cycles of amazonian forests and pastures. Nature 372:666-669.

NIMER, E. 1979. Climatologia do Brasil. IBGE, Rio de Janeiro.

OLIVEIRA, A.A. \& MORI, S.A. 1999. A central Amazonian terra firme forest. I. High tree species richness on poor soils. Biodiversity and Conservation 8:1219-1244.

OLIVEIRA, A.A. \& NELSON, B.W. 2001. Floristic relationships of terra firme forests in the Brazilian Amazon. Forest Ecology and Management 146:169179.

OLIVEIRA, A.N. \& AMARAL, I.L. 2004. Florística e fitossociologia de uma floresta de vertente na Amazônia Central, Amazonas, Brasil. Acta Amazonica 34:21-34.

OLIVEIRA-FILHO, A.T. \& RATTER, J.A. 1995. A study of the origin of central Brazilian forests by the analysis of plant species distribution patterns. Edinburgh Journal of Botany 52:141-194.

OLIVEIRA-FILHO, A.T. \& RATTER, J.A. 2000. Padrões florísticos das matas ciliares da região do cerrado e a evolução das paisagens do Brasil Central durante o Quaternário Tardio. In Matas ciliares: conservação e recuperação (R.R. Rodrigues \& H.F. Leitão-Filho, eds.). Edusp/Fapesp, São Paulo, p.73-89.

OLIVEIRA-FILHO, A.T., CURI, N., VILELA, E.A. \& CARVALHO, D.A. 2001. Variation in tree community composition and structure with changes in soil properties within a fragment of semideciduous forest in south-eastern Brazil. Edinburgh Journal of Botany 58:139-158.

OLIVEIRA-FILHO, A.T., JARENKOW, J.A. \& RODAL, M.J.N. 2006. Floristic relationships of seasonally dry forests of Eastern South America based on tree species distribution patterns. In Neotropical savannas and dry forests: plant diversity, biogeography, and conservation (R.T. Pennington, G.P. Lewis \& J.A. Ratter, eds.). CRC Press, Boca Raton, v.69, p.151-184.
PINTO, J.R.R. \& OLIVEIRA-FILHO, A.T. 1999. Perfil florístico e estrutura da comunidade arbórea de uma floresta de vale no Parque Nacional da Chapada dos Guimarães, Mato Grosso, Brasil. Revista Brasileira de Botânica 22:53-67.

RAMOS, P.C.M. 1995. Vegetation communities and soils in the National Park of Brasília. Ph.D. thesis, University of Edinburgh, Edinburgh.

RATTER, J.A. 1987. Notes on the vegetation of the Parque Nacional do Araguaia (Brazil). Notes from the Royal Botanic Garden, Edinburgh 44:311-342.

RIBEIRO, J.F. \& WALTER, B.M.T. 1998. Fitofisionomias do bioma Cerrado. In Cerrado: ambiente e flora (S.M. Sano \& S.P. Almeida, eds.). Embrapa Cerrado, Planaltina, p.89-196.

RIBEIRO, J.F., SILVA, J.C.S. \& BATMANIAN, G.J. 1985. Fitossociologia de tipos fisionômicos de cerrado em Planaltina-DF. Revista Brasileira de Botânica 8:131142.

RIZZINI, C.T. 1979. Tratado de fitogeografia do Brasil: aspectos sociológicos e florísticos. Edusp, São Paulo, v.2.

RODRIGUES, R.R. \& NAVE, A.G. 2000. Heterogeneidade florística das matas ciliares. In Matas ciliares: conservação e recuperação (R.R. Rodrigues \& H.F. Leitão-Filho, eds.). Edusp/Fapesp, São Paulo, p.45-71.

ROSSATO, D.R., TONIATO, M.T.Z. \& DURIGAN. 2008. Flora fanerogâmica não-arbórea do cerrado na Estação Ecológica de Assis, estado de São Paulo. Revista Brasileira de Botânica 31:409-424.

ROSSI, M. \& QUEIROZ-NETO, J.P. 2001. Relações solo/ paisagem em regiões tropicais úmidas: o exemplo da Serra do Mar em São Paulo, Brasil. Revista do Departamento de Geografia 14:11-23.

SALGADO-LABOURIAU, M.L., BARBERI, M., VICENTINI, K.R.F. \& PARIZZI, M.M. 1997. A dry climatic event during the late quaternary of tropical Brazil. Review of Paleobotany and Palynology 99:115129.

SALIS, S.M., SHEPHERD, G.J. \& JOLY, C.A. 1995. Floristic comparison of mesophytic semideciduous forests of the interior of the state of São Paulo, Southeast Brazil. Vegetatio 119:155-164.

SALOMÃO, R.P. \& LISBOA, P.L.B. 1988. Análise ecológica da vegetação de uma floresta pluvial tropical de terra firme, Rondônia. Boletim do Museu Paraense Emílio Goeldi, série Botânica 4:195-233.

SALOMÃO, R.P., SILVA, M.F.F. \& ROSA, P.L.B. 1988. Inventário ecológico em Floresta Pluvial Tropical de Terra Firme, Serra Norte, Carajás, Pará. Boletim do Museu Paraense Emílio Goeldi, série Botânica 4:1-46.

SEPLAN, SECRETARIA DE ESTADO DE PLANEJAMENTO E COORDENAÇÃO GERAL DE MATO GROSSO. 1999. Dados secundários do DSEE/ MT: Zoneamento - Divulga. CD-Rom. Versão 1.01. 
SHEPHERD, G.J. 1995. FITOPAC 1: manual do usuário. Campinas, Unicamp.

SILVA, A.F. \& SHEPHERD, G.J. 1986. Comparações florísticas entre algumas matas brasileiras utilizando análise de agrupamento. Revista Brasileira de Botânica 9:81-86.

SILVA, A.S.L, LISBOA, P.L.B. \& MACIEL, U.N. 1992. Diversidade florística e estrutura em floresta densa da bacia do Rio Juruá. Boletim do Museu Paraense Emílio Goeldi, série Botânica 8:203-258.

SILVA, J.M.C. 1996. Distribuition of Amazonian and Atlantic birds in gallery forests of the cerrado region, South America. Ornitologia Neotropical 7:1-18.

SILVA JÚNIOR, M.C., FURLEY, P.A. \& RATTER, J.A. 1996. Variations in tree communities and soils with slope in Gallery Forest, Federal District, Brazil. In Advances in Hill Slope Processes. (M.G. Anderson \& S.M. Brooks, eds.). John Wiley \& Sons, Bristol, v.1, p.451-469.
SNEATH, P.H.A. \& SOKAL, R.R. 1973. Numerical taxonomy. W.H. Freeman, San Francisco.

TERBORGH, J. \& ANDRESEN, E. 1998. The composition of Amazonian forests: patterns at local and regional scales. Journal of Tropical Ecology 14:645-664.

TORRES, R.B., MARTINS, F.R. \& KINOSHITA, L.S. 1997. Climate, soil and tree flora relationships in forests in the state of São Paulo, southeastern Brasil. Revista Brasileira de Botânica 20:41-49.

TUOMISTO, H. \& RUOKOLAINEN, K. 1997. The role of ecological knowledge in explaining biogeography and biodiversity in Amazonia. Biodiversity and Conservation 6:347-357.

TUOMISTO, H., RUOKOLAINEN, K. \& YLI-HALLA, M. 2003. Dispersal, environment, and floristic variation of western Amazonian Forests. Science 299:241-244.

VELOSO, H.P., RANGEL FILHO, A.L.R. \& LIMA, J.C.A. 1991. Classificação da vegetação brasileira, adaptada a um sistema universal. IBGE, Rio de Janeiro. 